\title{
Differences in Staff-Assessed Pain Behaviors among Newly Admitted Nursing Home Residents by Level of Cognitive Impairment
}

\author{
Reynolds A. Morrison ${ }^{a} \quad$ Bill M. Jesdale ${ }^{a} \quad$ Catherine E. Dubéa Anthony P. Nunes ${ }^{a}$

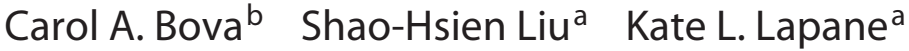 \\ ${ }^{a}$ Division of Epidemiology, Department of Population and Quantitative Health Sciences, University of \\ Massachusetts Medical School, Worcester, MA, USA; ${ }^{b}$ School of Nursing, University of Massachusetts Medical \\ School, Worcester, MA, USA
}

\section{Keywords}

Pain · Nursing homes · Cognitive impairment · Dementia

\begin{abstract}
Objective: Pain is common among nursing home residents with cognitive impairment and dementia. Pain is often underdiagnosed and undertreated, which may lead to adverse health outcomes. Nonverbal behaviors are valid indicators of pain, but the extent to which these behavioral expressions vary across levels of cognitive impairment is unknown. This study sought to examine differences in the prevalence of pain behaviors among nursing home residents with varying levels of cognitive impairment. Methods: The Minimum Data Set, version 3.0, was used to identify newly admitted nursing home residents with staff-assessed pain (2010$2016, n=1,036,806)$. Staff-assessed pain behaviors included nonverbal sounds, vocal complaints, facial expressions, and protective body movements or postures over a 5-day lookback period for residents unable or unwilling to self-report pain. The Cognitive Function Scale was used to categorize residents as having no/mild, moderate, or severe cognitive impairment. Modified Poisson models provided adjusted prevalence ratios (aPR) and 95\% Cls. Results: Compared to residents with no/mild cognitive impairments (any pain:
\end{abstract}

48.1\%), residents with moderate cognitive impairment (any pain: 42.4\%; aPR: 0.94 [95\% Cl 0.93-0.95]) and severe cognitive impairment (any pain: 38.4\%; aPR: 0.86 [95\% Cl 0.85$0.88]$ ) were less likely to have any pain behavior documented. Vocal pain behaviors were common $(43.5 \%$ in residents with no/mild cognitive impairment), but less so in those with severe cognitive impairment (20.1\%). Documentation of facial expressions and nonverbal pain behaviors was more frequent for residents with moderate and severe cognitive impairment than those with no/mild cognitive impairment. Conclusions: The prevalence of behaviors indicative of pain differs by level of cognitive impairment. Pain evaluation and management plays an important role in treatment and care outcomes. Future work should examine how practitioners' perceptions of pain behaviors influence their ratings of pain intensity and treatment choices.

(c) 2020 S. Karger AG, Basel

\section{Introduction}

Nearly 5 million adults aged $\geq 65$ years were living with Alzheimer's disease and related dementias in 2014 [1]. This is estimated to increase to 13.9 million people by 2060 [1]. Approximately 48\% of nursing home residents karger@karger.com

(C) 2020 S. Karger AG, Basel

www.karger.com/dem

Karger ${ }^{\prime}=$
Kate L. Lapane

Division of Epidemiology

University of Massachusetts Medical School

Worcester, MA 01655 (USA)

Kate.lapane@umassmed.edu 


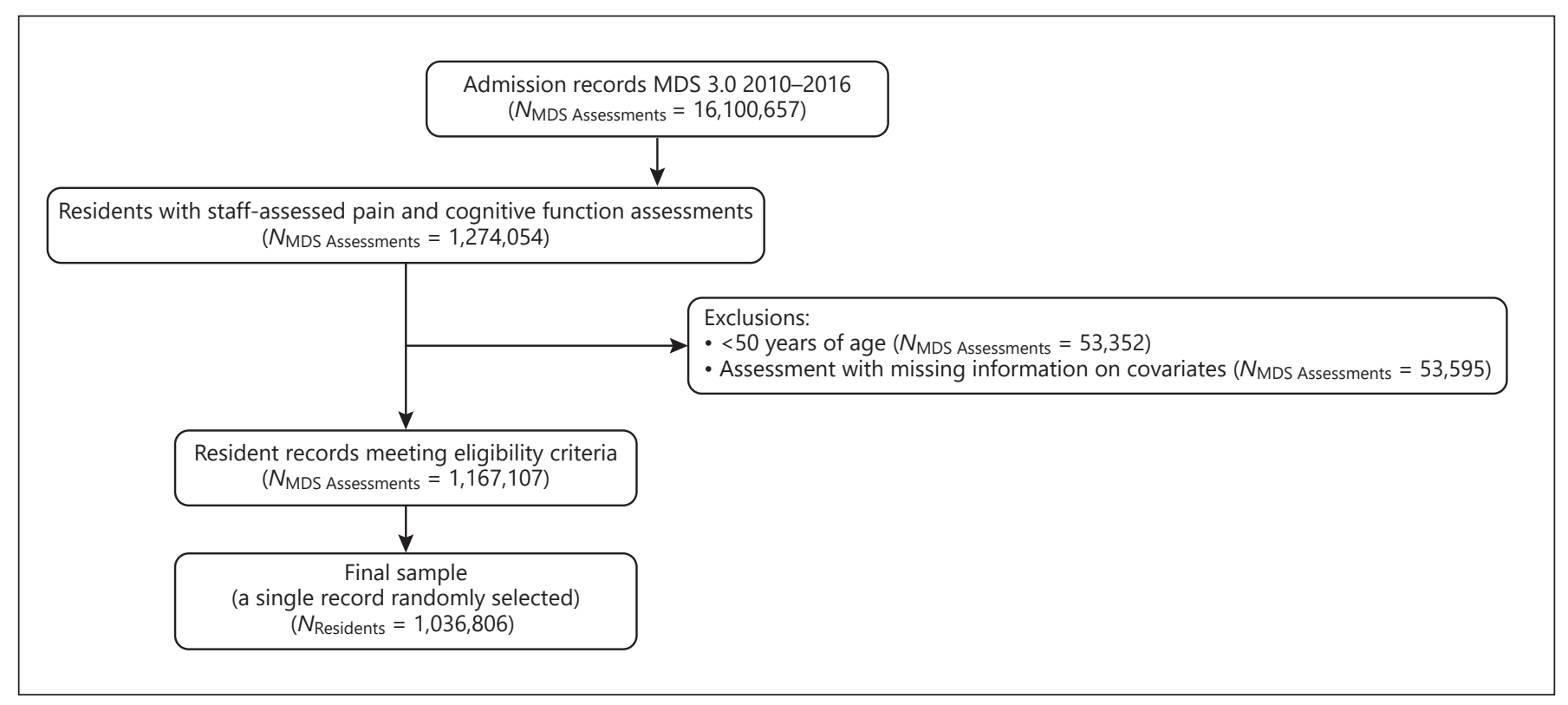

Fig. 1. Sample selection procedure for newly admitted nursing home residents assessed for pain behaviors by staff.

suffer from dementia [2]. People with dementia and cognitive impairment often have comorbid conditions, which increases the likelihood that their symptoms may be missed or misdiagnosed [3].

Between 40 and $50 \%$ of nursing home residents with cognitive impairment experience pain regularly [4-6]. Because communication and intellectual difficulties make pain assessment challenging $[4,7,8]$, pain is underdiagnosed and undertreated in those with cognitive impairment [9-11]. This contributes to various adverse outcomes, including depression [12], decreased quality of life [13], and increased functional limitations [14].

In people unable to self-report pain due to language, memory, or pain perception deficits, behaviors such as facial expressions, vocalizations, and body movements can indicate pain [15] and are thought to be valid and reliable alternatives to self-reported pain assessment [1618]. The ability of medical staff to accurately assess pain depends on their awareness of behaviors that may be present [19]. The extent of cognitive impairment may impact pain behaviors displayed; a small number of studies published on this topic were limited to selected participants with small sample sizes [20-22]. For example, verbal cues and body movements may be less prevalent among those with severe cognitive impairment [21]. The results with respect to facial expressions of pain and cognitive impairment are mixed [22]. Using a national data resource including virtually all nursing home residents in the United States, this study sought to provide a comprehensive description of nonverbal pain behaviors among newly admitted nursing home residents and to describe differences in behaviors by level of cognitive impairment.

\section{Methods}

The University of Massachusetts Medical School Institutional Review Board approved the study protocol.

Data

The Minimum Data Set (MDS) 3.0 is a mandatory standardized assessment of clinical and functional status indicators of residents in Medicare/Medicaid-certified nursing homes and hospitals with Medicare swing bed agreements [23]. The MDS allows for direct input of the "resident's voice" to identify resident needs and inform resident-focused care planning [23]. Information on active diagnoses, treatments, health-related quality of life, cognitive function, depression, and pain is collected directly through resident interviews, from family members, or staff interviews [23, 24] and has high interrater reliability and clinical validity [25].

\section{Sample}

MDS 3.0 assessments of newly admitted residents, aged $\geq 50$ years of age, with staff-assessed pain from 2010 to 2016 were used $(n=1,036,806$; Fig. 1$)$. Staff are required to complete MDS assessments within 14 days after admission.

\section{Pain Behaviors}

Resident-reported pain is the most reliable means of evaluating pain, with staff-assessed pain for those unable or unwilling to report 
Table 1. Characteristics of nursing home residents with staff-assessed pain $(n=1,036,806)$

\begin{tabular}{|c|c|c|c|}
\hline \multirow[t]{2}{*}{ Characteristic } & \multicolumn{3}{|c|}{ Level of cognitive impairment } \\
\hline & $\begin{array}{l}\text { no/mild } \\
(n=224,239)\end{array}$ & $\begin{array}{l}\text { moderate } \\
(n=268,167)\end{array}$ & $\begin{array}{l}\text { severe } \\
(n=544,400)\end{array}$ \\
\hline \multicolumn{4}{|l|}{ Age } \\
\hline $50-64$ years & 18.3 & 10.0 & 9.8 \\
\hline $65-74$ years & 23.5 & 15.8 & 14.7 \\
\hline $75-84$ years & 30.9 & 32.4 & 32.7 \\
\hline $85+$ years & 27.3 & 41.8 & 42.8 \\
\hline Women & 59.5 & 58.4 & 61.6 \\
\hline \multicolumn{4}{|l|}{ Race/ethnicity } \\
\hline Non-Hispanic White & 79.7 & 76.7 & 74.3 \\
\hline Non-Hispanic Black & 12.6 & 13.1 & 15.3 \\
\hline Hispanic or Latino & 4.9 & 6.2 & 6.7 \\
\hline Non-Hispanic other & 2.9 & 4.0 & 3.7 \\
\hline Married* & 34.0 & 34.6 & 36.0 \\
\hline Admitted from acute hospital & 89.4 & 80.0 & 76.2 \\
\hline Rejects care & 6.2 & 17.1 & 17.3 \\
\hline \multicolumn{4}{|c|}{ Activities of daily living limitations } \\
\hline Moderate & 55.1 & 50.6 & 39.5 \\
\hline Severe & 24.2 & 41.5 & 57.0 \\
\hline \multicolumn{4}{|l|}{ Diagnoses } \\
\hline Dementia/Alzheimer's & 13.3 & 50.6 & 64.7 \\
\hline Anxiety disorder & 17.7 & 20.9 & 21.9 \\
\hline Depression & 28.0 & 31.8 & 29.9 \\
\hline Hospice & 3.3 & 6.1 & 9.6 \\
\hline Post-acute stay & 60.6 & 59.0 & 54.6 \\
\hline
\end{tabular}

Values represent percentages. They may not total $100 \%$ due to rounding. * Missing data: marital status (none/ mild $=7,866$, moderate $=7,424$, severe $=15,347$ ).

pain serving as a suitable alternative [23]. Nursing home staff assess pain behaviors if [23] (1) the resident is rarely/never understood (item B0700) or an interpreter is needed but unavailable (item J0200), (2) resident is unable to answer if they had any pain in the last 5 days (item J0300), or (3) the resident self-reported pain interview was not completed (section J0700). The staff assess pain behaviors during a 5-day look-back period (items J0800 a-c) by (1) reviewing medical records for documentation of pain behaviors and confirming with direct care staff (across all shifts) who work most closely with the resident during activities of daily living (ADL), (2) interviewing direct care staff for information of pain indicators that may not have been documented in the medical record, and (3) observing the resident during ADL performance or wound care.

Four pain behaviors include (1) nonverbal sounds documented if the resident was crying, whining, gasping, moaning, or groaning, (2) vocal complaints of pain documented if the resident made vocal complaints of pain such as "that hurts," "ouch," or "stop," (3) facial expressions including indicators such as grimaces, winces, wrinkled forehead, furrowed brow, clenched teeth or jaw, and (4) protective body movements or postures including bracing, guarding, rubbing or massaging a body part/area, and clutching or holding a body part during movement. Staff also document if none of the corresponding pain signs were observed or reported (section J0800Z) and the number of days that residents complained or showed evidence of pain (none, 1-2 days, 3-4 days, daily). These pain behaviors have high validity and reliability [26].

\section{Cognitive Impairment}

The Brief Interview of Mental Status (BIMS) [27] was used for residents who could communicate. The BIMS, with scores ranging from 0 (no items correct) to 15 (all items correct), is a performancebased cognitive screen that assesses residents' temporal orientation and recall [27]. For those unable to complete the BIMS, the Cognitive Performance Scale (CPS) was used. The CPS assesses how the cognitive status of residents affects their short- and long-term memory, decision-making ability, and performance of daily tasks such as eating [28]. Possible CPS scores range from 0 (intact) to 6 (very severe impairment). BIMS and CPS scores were combined to form the Cognitive Function Scale. Residents were categorized as no/mild (BIMS $13-15$ or CPS $0-2$ ), moderate (BIMS 8-12 or CPS 3-4), or severe (BIMS 0-7 or CPS 5-6) cognitive impairment [29].

\section{Sociodemographic and Clinical Characteristics}

Sociodemographic characteristics included the race/ethnicity of residents (non-Hispanic White, non-Hispanic Black, Hispanic/Latino of any race(s), or non-Hispanic other), age in years (50-64, $65-74,75-84$, and $\geq 85$ years), sex, and marital status. Clinical characteristics included rejection of care, hospice care in past 14 days, 
Table 2. Prevalence of potentially painful conditions, by level of cognitive impairment $(n=1,036,806)$

\begin{tabular}{|c|c|c|c|}
\hline \multirow[t]{2}{*}{ Condition } & \multicolumn{3}{|c|}{ Level of cognitive impairment } \\
\hline & $\begin{array}{l}\text { no/mild } \\
(n=224,239)\end{array}$ & $\begin{array}{l}\text { moderate } \\
(n=268,167)\end{array}$ & $\begin{array}{l}\text { severe } \\
(n=544,400)\end{array}$ \\
\hline Cancer & 11.6 & 9.5 & 7.9 \\
\hline \multicolumn{4}{|l|}{ Cardiovascular } \\
\hline Heart failure & 21.6 & 18.4 & 15.3 \\
\hline Coronary artery disease & 23.7 & 22.8 & 20.6 \\
\hline Venous thromboembolism & 3.9 & 3.2 & 3.2 \\
\hline Peripheral vascular/arterial disease & 7.5 & 6.3 & 5.6 \\
\hline Inflammatory bowel disease/ulcerative colitis & 1.1 & 0.8 & 0.6 \\
\hline Skin problems* & 30.7 & 18.4 & 16.9 \\
\hline \multicolumn{4}{|l|}{ Musculoskeletal } \\
\hline Arthritis & 22.9 & 19.8 & 18.7 \\
\hline Osteoporosis & 8.7 & 10.2 & 10.3 \\
\hline Fracture (hip and other) & 13.9 & 14.5 & 13.7 \\
\hline Urinary tract infection (last 30 days) & 12.8 & 18.1 & 19.1 \\
\hline
\end{tabular}

Values represent percentages. * Includes foot problems (infection of the foot, diabetic foot ulcers, other open lesions of the foot), burns (second or third degree), surgical wounds, and open lesions other than ulcers, rashes, and cuts.

source of admission (acute hospital, or other community [private home/apt., board/care, assisted living, group home], another nursing home or swing bed, psychiatric hospital, inpatient rehabilitation facility, intellectual disability/developmental disability facility, hospice, long-term care hospital, other), diagnosis of dementia or Alzheimer's disease, anxiety disorder, and depression. ADL function was determined using 4 items on the MDS ADL short form personal hygiene, toilet use, locomotion on unit, and eating - to create a performance scale (range 0-6) [30]. ADL function was then categorized as minimal limitation (0-2), moderate limitation (3-4), or severe limitation (5-6). Potentially painful health conditions such as cancer and cardiovascular diseases were included.

\section{Analysis}

Descriptive statistics were used to examine the prevalence of sociodemographic characteristics, clinical characteristics, potentially painful conditions, and frequency of pain behaviors by level of cognitive impairment. Absolute differences $\geq 5 \%$ were considered clinically relevant. Adjusted prevalence ratios (aPR) and 95\% CIs $[31,32]$ using modified Poisson models, implemented with generalized estimating equations with an exchangeable covariance matrix to account for clustering within nursing homes, were computed to compare each pain behavior among the different cognitive impairment subgroups.

\section{Results}

The majority of newly admitted nursing home residents with staff-reported pain were women $(60.3 \%)$, nonHispanic White $(76.1 \%)$, aged $\geq 75$ years $(71.5 \%)$, and with moderate to severe limitations in ADL function (91.6\%). Most were referred to the nursing home from an acute care hospital (80.0\%). Most had severe cognitive impairment (53\%) and among those who did, 57\% had extensive ADL limitations, compared to $24 \%$ of those with no/mild cognitive impairment who had extensive ADL limitations. Seventeen percent of residents with severe cognitive impairment rejected care, whereas $6.2 \%$ of those with no/mild cognitive impairment rejected care (Table 1).

Except for a few conditions, the prevalence of potentially painful conditions appeared similar across levels of cognitive impairment (Table 2). About $9.1 \%$ of residents had been diagnosed with cancer $(11.6 \%$ among those with no/mild cognitive impairment, $7.9 \%$ among those with severe cognitive impairment). Heart failure was a common condition ( $22 \%$ among those with no/mild cognitive impairment, $15 \%$ among those with severe cognitive impairment). Thirteen percent of residents with no/mild cognitive impairment had a urinary tract infection within the past 30 days, while $19 \%$ of residents with severe cognitive impairment had the condition.

\section{Prevalence of Pain Behaviors}

Overall, $41.5 \%$ had at least one pain behavior documented. While $53.8 \%$ of residents receiving hospice care had any pain behavior documented, $40.5 \%$ of residents 
Table 3. Association between cognitive impairment and pain behaviors among nursing home residents

\begin{tabular}{|c|c|c|c|}
\hline & \multicolumn{3}{|c|}{ Level of cognitive impairment } \\
\hline & $\begin{array}{l}\text { no/mild } \\
(n=224,239)\end{array}$ & $\begin{array}{l}\text { moderate } \\
(n=268,167)\end{array}$ & $\begin{array}{l}\text { severe } \\
(n=544,400)\end{array}$ \\
\hline \multicolumn{4}{|c|}{ Vocal complaints } \\
\hline Percentage & 43.5 & 29.5 & 20.1 \\
\hline \multicolumn{4}{|c|}{ Prevalence ratio $(95 \% \mathrm{CI})$} \\
\hline Crude & 1.00 & $0.68(0.67-0.69)$ & $0.46(0.45-0.47)$ \\
\hline Adjusted* & 1.00 & $0.77(0.76-0.78)$ & $0.56(0.55-0.57)$ \\
\hline \multicolumn{4}{|c|}{ Facial expressions } \\
\hline Percentage & 11.1 & 21.3 & 23.6 \\
\hline \multicolumn{4}{|c|}{ Prevalence ratio $(95 \% \mathrm{CI})$} \\
\hline Crude & 1.00 & $1.92(1.85-1.99)$ & $2.13(2.05-2.22)$ \\
\hline Adjusted* & 1.00 & $1.80(1.74-1.86)$ & $1.90(1.84-1.97)$ \\
\hline \multicolumn{4}{|c|}{ Nonverbal sounds } \\
\hline Percentage & 5.6 & 12.6 & 15.4 \\
\hline \multicolumn{4}{|c|}{ Prevalence ratio $(95 \% \mathrm{CI})$} \\
\hline Crude & 1.00 & $2.23(2.15-2.32)$ & $2.73(2.63-2.85)$ \\
\hline Adjusted $^{*}$ & 1.00 & $1.99(1.92-2.05)$ & $2.23(2.16-2.32)$ \\
\hline \multicolumn{4}{|c|}{ Protective body movements or postures } \\
\hline Percentage & 4.7 & 8.2 & 8.6 \\
\hline \multicolumn{4}{|c|}{ Prevalence ratio $(95 \% \mathrm{CI})$} \\
\hline Crude & 1.00 & $1.76(1.68-1.84)$ & $1.83(1.75-1.92)$ \\
\hline Adjusted* & 1.00 & $1.67(1.60-1.74)$ & $1.72(1.65-1.80)$ \\
\hline \multicolumn{4}{|c|}{ Any pain behavior } \\
\hline Percentage & 48.1 & 42.4 & 38.4 \\
\hline \multicolumn{4}{|c|}{ Prevalence ratio $(95 \% \mathrm{CI})$} \\
\hline Crude & 1.00 & $0.88(0.87-0.90)$ & $0.80(0.78-0.82)$ \\
\hline Adjusted* & 1.00 & $0.94(0.93-0.95)$ & $0.86(0.85-0.88)$ \\
\hline
\end{tabular}

not on hospice did. Vocal complaints were the most common pain behavior documented (27.6\%), followed by facial expressions (20.3\%), nonverbal sounds (12.6\%), and protective body movements or postures (7.6\%). Differences in the prevalence of pain behaviors were apparent by receipt of hospice care for facial expressions of pain (receiving hospice: 36.7\%; not receiving hospice: 19.0\%) and nonverbal sounds (hospice: 28.3\%; no hospice: $11.3 \%$ ), but not for vocal complaints (hospice: $24.5 \%$; no hospice: $27.9 \%$ ) or protective body movements (hospice: 10.5\%; no hospice: $7.4 \%$ ).

At least one pain behavior was documented in $48.1 \%$ of residents with no/mild and $38.4 \%$ of residents with severe cognitive impairment (Table 3). Pain behaviors were observed daily in $17.8 \%$ of residents with no/mild cognitive impairment and $8.7 \%$ of residents with severe cognitive im- pairment (Fig. 2). Vocal complaints of pain were observed in $43.5 \%$ of residents with no/mild cognitive impairment and $20.1 \%$ of residents with severe cognitive impairment (Table 3). Facial expressions of pain were documented in $11.1 \%$ of residents with no/mild cognitive impairment and $23.6 \%$ of residents with severe cognitive impairment. Nonverbal sounds were documented in $5.6 \%$ of residents with no/mild cognitive impairment and $15.4 \%$ of residents with severe cognitive impairment. Among those with any pain behaviors, facial expressions, nonverbal sounds, and protective body movements were more common among those without verbal complaints compared to those with verbal complaints (facial expressions [77.9 vs. $34.3 \%$ ]; nonverbal sounds [51.8 vs. $19.5 \%$ ]; protective body movements or postures [24.6 vs. $15.2 \%]$ ). These differences remained after stratifying by level of cognitive impairment (Table 4). 
Fig. 2. Frequency of any pain behaviors by level of cognitive impairment.

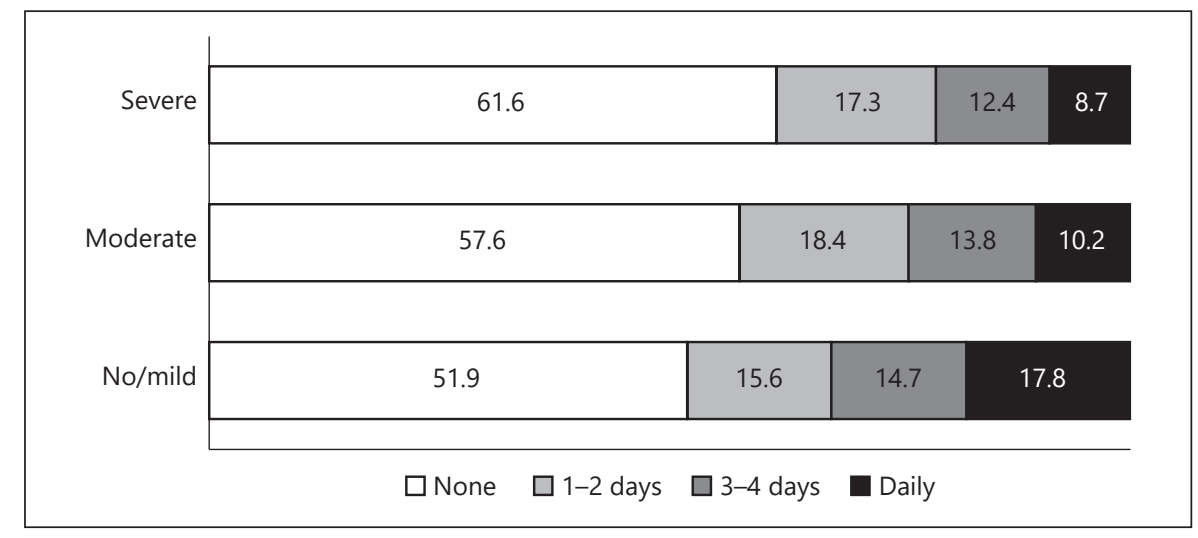

Table 4. Pain behaviors by vocal complaints and cognitive impairment among 430,377 residents with any pain

\begin{tabular}{lll}
\hline Pain behavior & No & Yes \\
\hline Vocal complaints & $n=144,061$ & $n=286,316$ \\
Facial expressions & 77.9 & 34.3 \\
Nonverbal sounds & 51.8 & 19.5 \\
Protective body movements or postures & 24.6 & 15.2 \\
\hline No/mild cognitive impairment & $n=10,218$ & $n=97,543$ \\
Facial expressions & 77.7 & 17.3 \\
Nonverbal sounds & 49.8 & 7.8 \\
Protective body movements or postures & 26.0 & 8.0 \\
\hline Moderate cognitive impairment & $n=34,508$ & $n=79,177$ \\
Facial expressions & 78.4 & 37.8 \\
Nonverbal sounds & 49.8 & 21.0 \\
Protective body movements or postures & 26.5 & 16.2 \\
\hline Severe cognitive impairment & $n=99,335$ & $n=109,596$ \\
Facial expressions & 77.7 & 46.8 \\
Nonverbal sounds & 52.8 & 28.8 \\
Protective body movements or postures & 23.8 & 20.9 \\
\hline
\end{tabular}

Values represent percentages.

Table 3 shows that after adjustment for sociodemographic characteristics, clinical diagnoses, and the presence of potentially painful conditions, residents with moderate and severe cognitive impairment were less likely than those with no/mild cognitive impairment to have any pain behavior documented (aPR moderate: 0.94 [95\% CI 0.93-0.95]; aPR severe: 0.86 [95\% CI 0.85$0.88])$. Vocal complaints were less common in residents with moderate (aPR moderate: 0.77 [95\% CI 0.76-0.78]) and severe cognitive impairment (aPR severe: 0.56 [95\% CI 0.55-0.57]) than in residents with no/mild cognitive impairment. Facial expressions of pain were more com- mon in those with moderate and severe cognitive impairment relative to cognitively intact/mild residents (aPR moderate: 1.80 [95\% CI 1.74-1.86]; aPR severe: 1.90 [95\% CI 1.84-1.97]). Similar patterns were observed for nonverbal sounds and protective body movements.

\section{Discussion}

We found that among residents with staff-assessed pain, those with moderate and severe cognitive impairment were less likely than those with no/mild cognitive impairment to have any pain behavior documented. Differences in the prevalence of pain behaviors were observed by level of cognitive impairment. The most common pain behavior observed was vocal complaints, which was more frequently noted among individuals with no/ mild cognitive impairment, while facial expressions, nonverbal sounds, and protective body movements or postures were more common among those with moderate or severe cognitive impairment.

While self-report of pain is a more reliable indicator of pain than staff-assessed nonverbal behaviors [18, 23], for patients unable to communicate due to cognitive, developmental, or physiologic issues, nonverbal indicators are essential to assess pain [18]. Individuals with conditions that affect recall and pain responses, such as cognitive impairment or dementia, may not exhibit typical behaviors indicating pain $[7,17]$. Among persons with advanced cognitive impairment, the behaviors observed may be elicited by other conditions such as depression and anxiety $[7,33]$. In our study, differences in pain behavior prevalence by level of cognitive impairment persisted after adjustment for depression and anxiety. Fur- 
ther, pain behaviors were documented based on medical record review or observation of the resident during the performance of ADLs. For these observations, the pain behaviors were likely due to pain brought on by movement or activity. It is possible that pain behaviors exhibited during movement are different than pain behaviors exhibited at rest.

Protective body movements were the least frequently documented pain behavior. It is possible that such movements may have been observed, but not attributed to pain. In other research, rubbing, bracing, and restlessness were common indicators of pain in some [34,35], but not all studies [7, 36]. Facial expressions of pain were also more readily observed in some studies [7,34]. Cognitively impaired individuals may be more likely than non-impaired individuals to display anticipatory fear of pain and reduced social inhibition of nonverbal pain expressions, such as grimacing [22]. Facial expressions and bracing/ guarding may be more easily detected among cognitively impaired individuals than among those able to communicate their pain vocally [34]. Pain is more recognizable with vocal communication for those who are able [34]. Alternately, staff who noted vocal complaints of pain may have been less likely to document less frank expression of pain, even when present.

We found that among those with any pain behavior documented, facial expressions, nonverbal pain behaviors, and body movements were documented more frequently in those without vocal complaints than those with vocal complaints, regardless of level of cognitive impairment. It is possible that vocal complaints of painrelated words such as "that hurts," "ouch," "stop" are more indicative of pain than nonverbal sounds such as crying, groaning, and gasping, which could be indicators of depression. The use of appropriate assessment tools can help in the effective identification and management of pain among patients who are unable to selfreport [37]. The American Geriatrics Society recommends that pain assessment in cognitively impaired older adults include consideration of changes in interpersonal interactions, activity patterns, and mental status [15].

\section{Implications}

Our findings support the need for the further development of observational pain assessment tools. Various pain behavior assessment tools have been developed and used among cognitively impaired people, but vary in the nonverbal pain indicators included [37-40]. Because of the variability among individuals and how they may non- verbally express pain, assessment tools should incorporate a wide range of potential pain indicators [37]. Regardless, assessment tools do not objectively measure pain intensity, a limitation that can affect treatment decisions. Observational pain assessments tools need to capture the information to guide care for those requiring staff assessment of pain in people with cognitive impairment. Novel techniques such as those that automate and evaluate facial expressions may have a role in better detecting pain in those who cannot self-report [41].

The study strengths include the use of a large standardized dataset of almost all US nursing home residents. Limitations include a 5-day look-back review of medical records or interviews of caregivers used to document frequency of pain behaviors. This may result in underreporting of pain behaviors as they may not have been included in the medical record or recalled by proxies. Lastly, we focused on residents at admission. Pain assessments at admission may be more susceptible to misclassification due to limited prior interaction between nursing home staff and the newly admitted residents.

\section{Conclusion}

Our findings support the hypothesis that pain behaviors are observed differently among persons with varying levels of cognitive impairment. Considering how pain diagnosis and management plays an essential role in treatment and care outcomes, improvements in tools to evaluate pain in cognitively impaired residents in nursing homes is warranted. Pain and depression adversely affect the quality of life of nursing home residents $[13,42,43]$. How nursing home staff perceptions of pain behaviors influence treatment choice requires further study.

\section{Statement of Ethics}

This study was conducted ethically in accordance with the World Medical Association Declaration of Helsinki. The study protocol was approved by the University of Massachusetts Medical School Institutional Review Board. The study used administrative data sources collected for purposes other than research, was granted a HIPAA waiver for research, and written informed consent was not required.

\section{Conflict of Interest Statement}

The authors have no conflicts of interest to disclose. 


\section{Funding Sources}

This research was funded by a grant from the National Institutes of Health (NR016977) to Dr. Kate L. Lapane.

\section{Author Contributions}

Dr. Reynolds A. Morrison made substantial contributions to the conception and design of the work, conducted the analysis, wrote the initial draft, and approved the final version of the paper. Drs. Carol A. Bova and Bill M. Jesdale made substantial contribu- tions to the conception and design of the work, assisted with interpretation of the data, provided critical review of the initial draft, and approved the final version of the paper. Dr. Catherine E. Dubé made substantial contributions to the acquisition of the data, provided critical revisions to the initial draft, and approved the final version of the paper. Drs. Shao-Hsien Liu and Anthony P. Nunes made substantial contributions to the design of the work, assisted with interpretation of the data, provided critical review of the initial draft, and approved the final version of the paper. Dr. Kate L. Lapane made substantial contributions to the conception and design of the work, acquisition of the data, interpretation of the data, provided critical revisions to the initial drafts, and approved the final version of the paper.

\section{References}

1 Matthews KA, Xu W, Gaglioti AH, Holt JB, Croft JB, Mack D, et al. Racial and ethnic estimates of Alzheimer's disease and related dementias in the United States (2015-2060) in adults aged $\geq 65$ years. Alzheimers Dement. 2019 Jan;15(1):17-24.

2 Harris-Kojetin L, Sengupta M, Lendon JP, Rome V, Valverde R, Caffrey C. Long-term care providers and services users in the United States, 2015-2016. Hyattsville (Maryland): National Center for Health Statistics; 2019.

3 Boustani M, Schubert C, Sennour Y. The challenge of supporting care for dementia in primary care. Clin Interv Aging. 2007;2(4):631-6.

4 Corbett A, Husebo B, Malcangio M, Staniland A, Cohen-Mansfield J, Aarsland D, et al. Assessment and treatment of pain in people with dementia. Nat Rev Neurol. 2012 Apr;8(5):264-74.

5 Zwakhalen SM, Koopmans RT, Geels PJ, Berger MP, Hamers JP. The prevalence of pain in nursing home residents with dementia measured using an observational pain scale. Eur J Pain. 2009 Jan;13(1):89-93.

6 Erdal A, Flo E, Selbaek G, Aarsland D, Bergh S, Slettebo DD, et al. Associations between pain and depression in nursing home patients at different stages of dementia. J Affect Disord. 2017 Aug;218:8-14.

7 Shega JW, Rudy T, Keefe FJ, Perri LC, Mengin OT, Weiner DK. Validity of pain behaviors in persons with mild to moderate cognitive impairment. J Am Geriatr Soc. 2008 Sep;56(9):1631-7.

8 Kunz M, Mylius V, Scharmann S, Schepelman $\mathrm{K}$, Lautenbacher S. Influence of dementia on multiple components of pain. Eur J Pain. 2009 Mar;13(3):317-25.

9 Burfield AH, Wan TT, Sole ML, Cooper JW. Behavioral cues to expand a pain model of the cognitively impaired elderly in long-term care. Clin Interv Aging. 2012;7:207-23.

10 Husebo BS, Strand LI, Moe-Nilssen R, Borgehusebo S, Aarsland D, Ljunggren AE. Who suffers most? Dementia and pain in nursing home patients: a cross-sectional study. J Am Med Dir Assoc. 2008 Jul;9(6):427-33.

11 Reynolds KS, Hanson LC, DeVellis RF, Henderson M, Steinhauser KE. Disparities in pain management between cognitively intact and cognitively impaired nursing home residents. J Pain Symptom Manage. 2008 Apr;35(4): 388-96.

12 Hadjistavropoulos T, Voyer P, Sharpe D, Verreault $\mathrm{R}$, Aubin $\mathrm{M}$. Assessing pain in dementia patients with comorbid delirium and/or depression. Pain Manag Nurs. 2008 Jun;9(2): 48-54.

13 Klapwijk MS, Caljouw MA, Pieper MJ, van der Steen JT, Achterberg WP. Characteristics Associated with Quality of Life in Long-Term Care Residents with Dementia: A Cross-Sectional Study. Dement Geriatr Cogn Disord. 2016;42(3-4):186-97.

14 Zakoscielna KM, Parmelee PA. Pain variability and its predictors in older adults: depression, cognition, functional status, health, and pain. J Aging Health. 2013 Dec;25(8):132939.

15 AGS Panel on Persistent Pain in Older Persons. The management of persistent pain in older persons. J Am Geriatr Soc. 2002 Jun; 50(6 Suppl):S205-24.

16 Dunwoody CJ, Krenzischek DA, Pasero C, Rathmell JP, Polomano RC. Assessment, physiological monitoring, and consequences of inadequately treated acute pain. J Perianesth Nurs. 2008 Feb;23(1 Suppl):S15-27.

17 Bjoro K, Herr K. Assessment of pain in the nonverbal or cognitively impaired older adult [vi.]. Clin Geriatr Med. 2008 May;24(2):23762.

18 Herr K, Coyne PJ, McCaffery M, Manworren $\mathrm{R}$, Merkel S. Pain assessment in the patient unable to self-report: position statement with clinical practice recommendations. Pain Manag Nurs. 2011 Dec;12(4):230-50.

19 Kaasalainen S. Pain assessment in older adults with dementia: using behavioral observation methods in clinical practice. J Gerontol Nurs. 2007 Jun;33(6):6-10.

20 Achterberg WP, Pieper MJ, van Dalen-Kok AH, de Waal MW, Husebo BS, Lautenbacher $\mathrm{S}$, et al. Pain management in patients with dementia. Clin Interv Aging. 2013;8:1471-82.

21 Closs SJ, Cash K, Barr B, Briggs M. Cues for the identification of pain in nursing home residents. Int J Nurs Stud. 2005 Jan;42(1):3-12.
22 Hadjistavropoulos T, LaChapelle DL, MacLeod FK, Snider B, Craig KD. Measuring movement-exacerbated pain in cognitively impaired frail elders. Clin J Pain. 2000 Mar; 16(1):54-63.

23 Centers for Medicare and Medicaid Services (CMS). Long-term care facility resident assessment instrument 3.0 user's manual, version 1.14. 2016

24 Saliba D, Jones M, Streim J, Ouslander J, Berlowitz D, Buchanan J. Overview of significant changes in the Minimum Data Set for nursing homes version 3.0. J Am Med Dir Assoc. 2012 Sep;13(7):595-601.

25 Saliba D, Buchanan J. Making the investment count: revision of the Minimum Data Set for nursing homes, MDS 3.0. J Am Med Dir Assoc. 2012 Sep;13(7):602-10.

26 Saliba D, Buchanan J. Development and Validation of a Revised Nursing Home Assessment Tool: MDS 3.0. Baltimore (MD): Centers for Medicare and Medicaid Services; 2008.

27 Saliba D, Buchanan J, Edelen MO, Streim J, Ouslander J, Berlowitz D, et al. MDS 3.0: brief interview for mental status. J Am Med Dir Assoc. 2012 Sep;13(7):611-7.

28 Morris JN, Fries BE, Mehr DR, Hawes C, Phillips C, Mor V, et al. MDS Cognitive Performance Scale. J Gerontol. 1994 Jul;49(4):M17482.

29 Centers for Medicare \& Medicaid Services. Nursing home data compendium 2015 edition. https://doi.org/10.1093/geronj/49.4.M174.

30 Morris JN, Fries BE, Morris SA. Scaling ADLs Within the MDS. J Gerontol A Biol Sci Med Sci. 1999 Nov;54(11):M546-53.

31 Spiegelman D, Hertzmark E. Easy SAS calculations for risk or prevalence ratios and differences. Am J Epidemiol. 2005 Aug; 162(3): 199-200.

32 Coutinho LM, Scazufca M, Menezes PR Methods for estimating prevalence ratios in cross-sectional studies. Rev Saude Publica. 2008 Dec;42(6):992-8.

33 McGuire DB, Kaiser KS, Haisfield-Wolfe ME, Iyamu F. Pain Assessment in Noncommunicative Adult Palliative Care Patients. Nurs Clin North Am. 2016 Sep;51(3):397-431. 
34 Cohen-Mansfield J, Creedon M. Nursing staff members' perceptions of pain indicators in persons with severe dementia. Clin J Pain. 2002 Jan-Feb;18(1):64-73.

35 Mentes JC, Teer J, Cadogan MP. The pain experience of cognitively impaired nursing home residents: perceptions of family members and certified nursing assistants. Pain Manag Nurs. 2004 Sep;5(3):118-25.

36 Ford B, Snow AL, Herr K, Tripp-Reimer T. Ethnic Differences in Nonverbal Pain Behaviors Observed in Older Adults with Dementia. Pain Manag Nurs. 2015 Oct;16(5):692-700.

37 Herr K, Bjoro K, Decker S. Tools for assessment of pain in nonverbal older adults with dementia: a state-of-the-science review. J Pain Symptom Manage. 2006 Feb;31(2):170-92.
38 Abbey J, Piller N, De Bellis A, Esterman A, Parker D, Giles L, et al. The Abbey pain scale: a 1-minute numerical indicator for people with end-stage dementia. Int J Palliat Nurs. 2004 Jan;10(1):6-13.

39 Feldt KS. The checklist of nonverbal pain indicators (CNPI). Pain Manag Nurs. 2000 Mar; 1(1):13-21.

40 Snow AL, Weber JB, O'Malley KJ, Cody M, Beck C, Bruera E, et al. NOPPAIN: a nursing assistant-administered pain assessment instrument for use in dementia. Dement Geriatr Cogn Disord. 2004;17(3):240-6.
41 Atee M, Hoti K, Parsons R, Hughes JD. A novel pain assessment tool incorporating automated facial analysis: interrater reliability in advanced dementia. Clin Interv Aging. 2018 Jul;13:1245-58.

42 Wetzels RB, Zuidema SU, de Jonghe JF, Verhey FR, Koopmans RT. Determinants of quality of life in nursing home residents with dementia. Dement Geriatr Cogn Disord. 2010; 29(3):189-97.

43 Barca ML, Engedal K, Laks J, Selbæk G. Quality of life among elderly patients with dementia in institutions. Dement Geriatr Cogn Disord. 2011;31(6):435-42. 